Pensamiento Crítico No. 7, pág. 201 - 215

\title{
La Producción y el Comercio de los Productos Transgénicos
}

\author{
Mg. Enrique Palacios Lozada
}

Resumen: El rápido progreso de la biotecnología, llamada la Revolución Genética, tiene una relación directa con la bioseguridad y la biodiversidad.

El uso de la biotecnología en el sector agrícola genera grandes expectativas, pero también incertidumbres ante potenciales riesgos en la salud humana y en el medio ambiente.

La producción y el comercio de estos productos se encuentra altamente concentrado, donde las empresas transnacionales juegan un rol importante.

Palabras Claves: Transgénicos, biodiversidad, empresas transnacionales, derecho de propiedad.

\section{ANTECEDENTES}

En estas últimas décadas se han producido grandes transformaciones en las relaciones económicas internacionales donde predomina el proceso de globalización o mundialización. Donde un proceso nuevo pero irreversible hace visualizar un sistema mundial agroalimentario, que va integrando de modo creciente las estructuras agrícolas 


\section{Enrique Palacios Lozada}

agroalimentarias nacionales. Basado en la incorporación creciente de la ciencia (aplicada y básica) en los procesos productivos como resultado de la revolución científica- tecnológica, lo que permite la creación de nuevos productos $\mathrm{y} / \mathrm{o}$ procesos. Donde las empresas transnacionales juegan un rol preponderante.

La población mundial se ha duplicado entre 1960 y el 2000pasando de 3,000 millones a 6,000 millones, la producción de alimentos creció a una tasa superior a la de la población, producto de avances tecnológicos aplicados a la agricultura conocida como la "revolución verde". Sin embargo en la actualidad existen 800 millones de personas desnutridas.

Se estima que el año 2050 la población mundial será de 10,000 millones se prevee que la economía mundial crecerá en los próximos años a una tasa cercana al 3\%. El crecimiento económico y el aumento de la población inducirá a un incremento de la demanda de alimentos y que de persistir el actual patrón de distribución se requerirá una elevación de la producción de alimentos en un porcentaje superior al $50 \%$, si se considera además reducir la tasa de malnutrición.

La agrobiotecnología puede ser parte de la solución del problema de satisfacer las crecientes necesidades alimenticias de la población mundial. Desde hace unas décadas se están llevando a cabo nuevas investigaciones biotecnológicas con aplicaciones económicas.

El uso de la biotecnología agrícola genera grandes expectativas y también incertidumbre ante potenciales riesgos. Preocupan sus posibles repercusiones en la salud humana y en el medio ambiente.

El Convenio de la Diversidad Biológica (CDB) define la biotecnología como "toda aplicación tecnológica que utilice sistemas biológicos y organismos vivos o sus derivados para la creación o modificación de productos o procesos para usos específicos". Esta definición abarca una gama de técnicas usadas en la agricultura y en la industria de alimentos, como las técnicas ADN (Acido Desoxirribonucleico) y reproductivas y la manipulación y transferencia de genes. Con la ruptura de las barreras biológicas y el cruce entre especies se obtienen alimentos $\mathrm{u}$ organismos transgénicos. El nuevo organismo con el atributo de aquellas características genéticas deseadas es una variedad de cultivo idéntica a la tradicional, pero que incorpora nueva información genética.

Al utilizar organismos transgénicos en la producción agrícola se comprueban mejoras 


\section{La producción y el comercio de los productos transgénicos}

de algunas características originales. Hay mayor resistencia a ciertos pesticidas o herbicidas y a enfermedades o plagas (virus, hongos, insectos y parásitos). La producción se adapta mejor a condiciones medioambientales como: heladas, sequías y suelos y el contenido de nutrientes es mayor (alimentos funcionales).

Aspectos que influyen en la reducción de los costos de producción y en incremento de la producción y productividad, pero también plantean posibles riesgos de reducir la biodiversidad y de afectar el equilibrio biológico. Situaciones que generan debates encontrados, unos a favor y otros en contra del uso de productos transgénicos. Los que están a favor argumentan que su uso constituye una solución a la necesidad de incrementar la producción agrícola, reducir costos, y de obtener producción de mejor calidad. Los opositores (ambientalistas) sostienen que su uso provoca riesgos al medio ambiente, la biodiversidad y a la salud humana.

\section{INDUSTRIA BIOTECNOLÓGICA Y EMPRESAS TRANSNACIONALES}

A mediados de los 80 , fue en los centros de Investigación de las principales universidades de los países desarrollados, como también en pequeñas empresas de gran densidad de conocimientos formadas por investigadores provenientes de esos mismos centros universitarios, y con el apoyo financiero de las grandes empresas farmacéuticas y de producción de alimentos, donde se realizaron importantes progresos en biotecnología.

Años posteriores las industrias química, farmacéutica y de alimentos iniciaron un proceso de compras, fusiones y acuerdos de donde surgieron los grandes conglomerados actuales. $\mathrm{El}$ dinamismo de este proceso obedeció, entre otras razones, a la necesidad de apropiarse de las tecnologías desarrolladas por empresas más pequeñas, a la posibilidad de acceder a determinados mercados, y a las economías de escala logradas en la investigación básica.

La industria biotecnológica es manejada principalmente por un grupo reducido de empresas transnacionales, localizadas de preferencia en países industrializados. Estas empresas desarrollan y comercializan productos y procedimientos y se preocupan de generar eficiencia en la producción y lograr utilidades. 


\section{Enrique Palacios Lozada}

La inversión mundial actual en Investigación y Desarrollo en el sector biotecnológico, tanto pública como privada se sitúa en 10.000 millones de dólares. De esta suma, los Estados Unidos invierten alrededor de un 50\%, Europa el 25\% y Japón el 20\%. Inversión realizada esencialmente por las Empresas Transnacionales, las cuales a través de fusiones y alianzas se han convertido en Mega empresas.

\section{UBICACIÓN DE LAS SIETE PRINCIPALES EMPRESAS DE AGROQUÍMICOS SEGÚN VENTAS, 2000-2001}

(Millones de dólares)

\begin{tabular}{|c|c|c|c|}
\hline Empresas & $\begin{array}{c}\text { Ventas anuales } \\
\text { (millones de dólares) }\end{array}$ & Empresas & $\begin{array}{c}\text { Ventas anuales } \\
\text { (millones de dólares) }\end{array}$ \\
\hline 1. Syngenta (Suiza) & 5888 & 1. Syngenta (Suiza) & 5835 \\
\hline $\begin{array}{l}\text { 2. Monsanto } \\
\text { (Estados Unidos) }\end{array}$ & 3885 & 2. Aventis (Francia) & 3842 \\
\hline 3. Aventis (Francia) & 3701 & $\begin{array}{l}\text { 3. Monsanto } \\
\text { (Estados Unidos) }\end{array}$ & 3755 \\
\hline $\begin{array}{l}\text { 4. DuPont } \\
\text { (Estados Unidos) }\end{array}$ & 2511 & 4. BASF (Alemania) & 3105 \\
\hline $\begin{array}{l}\text { 5. Dow Agrochemical } \\
\text { (Estados Unidos) }\end{array}$ & 2271 & $\begin{array}{l}\text { 5. Dow Agrochemical } \\
\text { (Estados Unidos) }\end{array}$ & 2612 \\
\hline 6. Bayer (Alemania) & 2252 & $\begin{array}{l}\text { 6. DuPont } \\
\text { (Estados Unidos) }\end{array}$ & 2418 \\
\hline 7. BASF (Alemania & 2228 & 7. Baryer (Alemania) & 1917 \\
\hline
\end{tabular}

Fuente: Agrow-World Crop Protection News, PJB Publications Ltd., 5 de enero, 2 de marzo y 13 de abril de 2001. 
La producción y el comercio de los productos transgénicos

LAS DIEZ PRINCIPALES EMPRESAS DE SEMILLAS SEGÚN VENTAS, 2000

(Millones de dólares)

\begin{tabular}{|lr|}
\hline Empresa y País de Origen & Ventas \\
\hline 1. Dupont (Pioner H-Bred), Estados Unidos & 1938 \\
2. Pharmacia (Mosanto), Estados Unidos & 1600 \\
3. Sygenta, Suiza & 958 \\
4. Grupo Limagrain, Francia & 622 \\
5. Grupo Pulsar (Seminis) México & 474 \\
6. Advanta (Atra Zeneca y Cosun), Países Bajos y Reino Unido & 373 \\
7. Dow (más Cargill North America), Estados Unidos & 350 \\
8. KWS AG, Alemania & 332 \\
9. Delta \& Pine Land, Estados Unidos & 301 \\
10 Aventis, Francia & 267 \\
\hline
\end{tabular}

Fuente: FAFI Communique, “Globalization, Inc. Concentration in Corporate Power: The Unmentioned Agenda”. Julio de 2001.

\section{PRINCIPALES EMPRESAS PRODUCTORAS DE SEMILLAS TRANSGÉNICAS}

\begin{tabular}{|c|c|c|c|c|c|}
\hline Empresa & $\begin{array}{c}\text { Empresa de semillas } \\
\text { adquiridas o controladas }\end{array}$ & Maíz & Soja & Algodón & $\begin{array}{c}\text { Otras } \\
\text { oleaginosas } \\
\end{array}$ \\
\hline $\begin{array}{l}\text { AgrEve } \\
\text { (pertenece a Aventis } \\
\text { y actualmente forma } \\
\text { parte de Syngenta) }\end{array}$ & $\begin{array}{l}\text { Cargill } \\
\text { Metla Pesquiza } \\
\text { Semenstes Ribeirao } \\
\text { Semenstes Fartura } \\
\text { Biogenetic Technologies } \\
\text { BV (BGT) }\end{array}$ & $\begin{array}{l}X \\
X \\
X \\
X \\
X \\
X\end{array}$ & & & $X$ \\
\hline Zeneca & Grast $(50 \%)$ & $X$ & & & \\
\hline Novartis & $\begin{array}{l}\text { Northup King } \\
\text { Eridian Beghin }\end{array}$ & $X$ & & & $X$ \\
\hline
\end{tabular}




\section{Enrique Palacios Lozada}

\begin{tabular}{|l|l|c|c|c|c|}
\hline DuPont & $\begin{array}{l}\text { Pioneer Hi-Bred } \\
\text { Protein Technologies } \\
\text { International }\end{array}$ & $\mathrm{X}$ & $\mathrm{X}$ & & $\mathrm{X}$ \\
Mycogen & $\mathrm{X}$ & $\mathrm{X}$ & & $\mathrm{X}$ \\
Monsanto & $\begin{array}{l}\text { DeKalb } \\
\text { Asgrow }\end{array}$ & $\mathrm{X}$ & $\mathrm{X}$ & & \\
& $\begin{array}{l}\mathrm{X} \\
\text { Hoden's } \\
\text { Delta \& Pine Land } \\
\text { Calgene } \\
\text { Stoneville }\end{array}$ & $\mathrm{X}$ & $\mathrm{X}$ & $\mathrm{X}$ & $\mathrm{X}$ \\
& & & & $\mathrm{X}$ \\
& & & & $\mathrm{X}$ \\
\hline
\end{tabular}

Fuente: Wood McKenzie, Merril Lynch, 2000.

\section{ADQUISICIONES Y ALIANZAS ENTRE CORPORACIONES DEDICADAS}

A LA BIOTECNOLOGIA (Miles de millones de dólares)

\begin{tabular}{|c|c|c|}
\hline Compañía & Corporaciones involucradas & $\begin{array}{c}\text { Valor } \\
\text { estimado }\end{array}$ \\
\hline $\begin{array}{l}\text { Pharmacia Mosanto } \\
\text { Y Pharma Upjohn }\end{array}$ & $\begin{array}{l}\text { Adquisiciones: Agrocetus, Asgrow, Calgene, Dekalb, Delta \& } \\
\text { Pine Land, Holdens, Semenstes Agroceres, Selected } \\
\text { internacional Seeds Operations of Cargill y Plant Breeding } \\
\text { Internacional Cambridge (PBIC) Fusión: Con Pharma Upjohn } \\
\text { en febrero de } 2000\end{array}$ & \\
\hline $\begin{array}{l}\text { Syngenta } \\
\text { Novartis y Astra Zeneca }\end{array}$ & $\begin{array}{l}\text { Fusión: En } 1996 \text { Sandoz y Ciba Geigy formaron Novartis en } \\
\text { Diciembre de } 2000 \text { novartis se fusionó con Astra Zeneca, } \\
\text { empresa nacida de la fusión, en 1999, de Zeneca Group y } \\
\text { Astra AB. }\end{array}$ & m \\
\hline $\begin{array}{l}\text { Pioneer Hi-Bred } \\
\text { Dupont }\end{array}$ & Inversión conjuntas: para formar Optimum Quality Productos & 1,7 \\
\hline DuPont & $\begin{array}{l}\text { Adquisición: Protein Technologies Inc. Soybean and millar } \\
\text { processor }\end{array}$ & 1,5 \\
\hline $\begin{array}{l}\text { Aventis (Hoechst y } \\
\text { Rhone Poulenc) }\end{array}$ & $\begin{array}{l}\text { Fusión: En } 1999 \text { se formó Aventis a partir de Hoechst y Rhone } \\
\text { Poulenc. Adquisición: Su subsidiaria AgreVO ADQUIRIÓ pgs, } \\
\text { Sun Seeds y Cargill North American }\end{array}$ & 1,5 \\
\hline Seminis (ELM / Pulsar) & $\begin{array}{l}\text { Adquisición: Asgrow, Petoseed, Royal S. Luis, DNAP,Hun } \\
\text { gong and ChoonAng y Nath Sluis } \\
\text { Alianza: LSL Biotechnologies }\end{array}$ & 1,5 \\
\hline Dow Agrosciences & Mycogen, Performance Plants, Brazil-Hibrido \& Others & 0,8 \\
\hline Cargill/Mosanto & $\begin{array}{l}\text { Inversión conjunta: Para investigación y desarrollo. } 100 \\
\text { millones de dólares anuales cada uno. }\end{array}$ & 0,2 \\
\hline Otras & Adquisiciones y alianzas: Crop Genomics & 1,7 \\
\hline
\end{tabular}

Fuente: Cilve, James-CEPAL. 
La producción y el comercio de los productos transgénicos

\section{PRODUCCIÓN MUNDIAL}

Desde su aparición 1994, los cultivos transgénicos han experimentado un incremento significativo en la superficie mundial sembrada, lo que coloca a los productores agrícolas frente a un enorme desafío.

La superficie mundial pasó de 1.7 millones de hectáreas en 1996 a 67.7 millones de hectáreas en el 2003.

Los principales cultivos transgénicos producidos son: la soya, maíz, algodón y la colza ó canola. En menor escala están la papa, tomate, tabaco, papaya y calabaza. Siendo la soya la de mayor significación.

Estados Unidos, Argentina concentran cerca de $90 \%$ de la superficie mundial sembrada de transgénicos. El área plantada aumento 24 veces en el período 1996-2003, lo mismo que su siembra se ha extendido a otros países México, Australia, China, India, Malasia y Tailandia.

\section{PRINCIPALES PAÍSES}

\section{SUPERFICIE CULTIVADA CON TRANSGÉNICOS, 1996-2001}

(Millones de hectáreas y porcentajes)

\begin{tabular}{|l|r|r|r|r|r|r|r|r|}
\hline & 1996 & 1997 & 1998 & 1999 & 2000 & 2001 & 2002 & 2003 \\
\hline EE.UU. & 1,5 & 8,1 & 20,5 & 28,7 & 30,3 & 35,7 & 39,0 & 42,8 \\
Argentina & 0,1 & 1,4 & 4,3 & 6,7 & 10,0 & 11,8 & 13,5 & 13,9 \\
Canadá & 0,1 & 1,3 & 2,8 & 4,0 & 3,0 & 3,2 & 3,5 & 4,4 \\
Otros & 1,9 & 1,9 & 0,2 & 0,5 & 0,9 & 1,9 & 2,7 & 6,6 \\
Total & 2,8 & 12,7 & 27,8 & 39,8 & 44,2 & 52,6 & 58,7 & 67,7 \\
\hline
\end{tabular}

Fuente: Clive James, Global status of commercialized transgenic crops: 1999 y 2001. 
Enrique Palacios Lozada

PRINCIPALES CULTIVOS TRANSGÉNICOS:

AREA MUNDIAL TOTAL E IMPORTANCIA RELATIVA, 1996-2001

(Millones de hectáreas y porcentaje)

\begin{tabular}{|l|r|r|r|r|r|r|r|r|}
\hline & 1996 & 1997 & 1998 & 1999 & 2000 & 2001 & 2002 & 2003 \\
\hline Soja: Total & 6,11 & 66,9 & 70,8 & 72,0 & 73,3 & 72,4 & 72,0 & 76,0 \\
\hline Transgénica & 0,5 & 5,1 & 14,5 & 25,8 & 33,3 & 36,5 & 36,5 & 41,4 \\
Transgénica & 0,8 & 7,6 & 20,4 & 35,2 & 46,0 & 51,0 & 51,0 & 55,0 \\
Total (\%) & & & & & & & & \\
\hline Maiz: Total & 139,4 & 141,2 & 138,6 & 138,9 & 136,5 & 140,0 & 140,0 & 140,0 \\
\hline Transgénica & 0,3 & 3,2 & 8,3 & 11,1 & 10,3 & 9,8 & 12,4 & 15,5 \\
Transgénica & 0,9 & 2,3 & 6,0 & 8,0 & 7,4 & 7,0 & 9,0 & 11,0 \\
Total (\%) & & & & & & & & \\
\hline Algodón: & 34,5 & 33,8 & 33,5 & 32,9 & 34 & 34,0 & 34,0 & 34,0 \\
Total & & & & & & & & \\
\hline Transgénica & 0,8 & 1,4 & 2,5 & 3,7 & 5,3 & 6,8 & 6,8 & 7,2 \\
Transgénica & 2,3 & 4,1 & 7,5 & 11,2 & 15,6 & 20,0 & 20,0 & 21,0 \\
Total (\%) & & & & & & & & \\
\hline Colza: Total & 21,8 & 23,6 & 26,5 & 25,0 & 25,0 & 24,5 & 25,0 & 22,0 \\
\hline Transgénica & 0,1 & 1,2 & 2,4 & 3,4 & 2,8 & 2,7 & 3,0 & 3,6 \\
Transgénica & 0,5 & 5,9 & 9,0 & 13,6 & 11,2 & 11,0 & 12,0 & 16,0 \\
Total (\%) & & & & & & & & \\
\hline Total & 1,7 & 10,9 & 27,7 & 39,8 & 44,2 & 52,6 & 58,7 & 67,7 \\
Transgénicos & & & & & & & & \\
\hline
\end{tabular}

Fuente: FAO-CEPAL 
La producción y el comercio de los productos transgénicos

ESTADOS UNIDOS: SUPERFICIE CULTIVADA CON TRANSGÉNICOS, 1996-2003

(Millones de hectáreas)

\begin{tabular}{|l|r|r|r|r|r|r|r|r|}
\hline Cultivo / Año & $\mathbf{1 9 9 6}$ & $\mathbf{1 9 9 7}$ & $\mathbf{1 9 9 8}$ & $\mathbf{1 9 9 9}$ & $\mathbf{2 0 0 0}$ & $\mathbf{2 0 0 1}$ & $\mathbf{2 0 0 2}$ & $\mathbf{2 0 0 3}$ \\
\hline Soja & 0,40 & 3,64 & 10,12 & 15,000 & 16,3 & 20,4 & 22,1 & 24,1 \\
Maíz & 0,30 & 2,27 & 8,66 & 10,30 & 8,0 & 8,0 & 10,8 & 12,8 \\
Algodón & 0,73 & 1,23 & 2,00 & 3,25 & 3,8 & 4,4 & 4,1 & 4,2 \\
Total & $\mathbf{1 , 4 3}$ & $\mathbf{7 , 1 4}$ & $\mathbf{2 0 , 7 8}$ & $\mathbf{2 8 , 5 5}$ & $\mathbf{2 8 , 1}$ & $\mathbf{3 2 , 8}$ & $\mathbf{3 7 , 0}$ & $\mathbf{4 2 , 8}$ \\
\hline
\end{tabular}

Fuente: FAO-CEPAL

En América Latina, destaca Argentina con el 15\% del área total y México con cerca del $1 \%$. Argentina cuenta con la mayor superficie de cultivos transgénicos en América Latina y es el segundo productor de ellos a nivel mundial.

En el Perú país rico en biodiversidad prevalece una posición cautelosa. Sin embargo importamos productos transgénicos: Maíz, soya.

\section{COMERCIO}

Las ventas mundiales de productos transgénicos se elevaron notablemente estimándose en 20,000 millones de dólares. El mercado más importante es representado por las semillas, seguido por los insumos agrícolas microbiológicos.

Se estima que cerca de 5 mil combinaciones de plantas han sido manipuladas en los laboratorios. Sin embargo, se ha autorizado comercializar unas pocas plantas transgénicas como el maíz, la soya, la canola, el algodón y la papa. Los países que más han progresado en las ventas externas son los Estados Unidos, Argentina.

Estados Unidos, lidera la utilización de la ingeniería genética para producir alimentos transgénicos para exportación. El país bordea el $90 \%$ del comercio mundial de soya y maíz transgénico. 


\section{Enrique Palacios Lozada}

El comercio de los transgénicos se ve restringido por el aumento de regulaciones al interior de los países que van desde limitaciones al acceso hasta prohibiciones directas a la entrada a los mercados. Sin embargo, no existen previsiones de que se detenga su producción y comercialización, al contrario, en el corto plazo deben ingresar al mercado nuevos productos transgénicos.

Algunos investigadores opinan que con la tierra y el agua disponibles actualmente no se garantiza el abastecimiento de alimentos a la población actual y menos a una futura si se continúan utilizando los métodos tradicionales. Otros argumentan que una de las principales razones de la existencia de la crisis de alimentos no es la falta de alimentos sino la carencia de los ingresos.

Lo que busca el consumidor es que de aprobarse su venta, el alimento transgénico debe tener el mismo nivel de seguridad alimenticia que el alimento no modificado (equivalencia sustancial).

Las preocupaciones se empezaron a manifestar en la Cumbre de la Tierra en Río de Janeiro en 1992, y se concretaron específicamente, en el marco del Convenio de la Diversidad Biológica. Convenio que se restringió sólo a los movimientos transfronterizos de los productos transgénicos.

Una gran parte de los países en desarrollo están a favor de reglamentar el comercio de alimentos transgénicos, apoyados en los desconocidos efectos en la salud y en el medio ambiente. A estos países les preocupa que en el futuro se vuelvan dependientes de la biotecnología importada. Además, ya cuentan con un alto grado de dependencia respecto a los conocimientos científicos externos.

Los países comunitarios de la Unión Europea consideraban necesario una evaluación del riesgo fundamentado en el Principio de Precaución adicionado al conocimiento científico antes de permitir el ingreso a sus mercados de los productos transgénicos. 


\section{La producción y el comercio de los productos transgénicos}

La otra posición es a favor del libre comercio, que señala que el Principio Precautorio puede ser utilizado como una barrera legítima al comercio sin contar con una base científica sólida, también tienen una actitud resistente a que se incluya el etiquetado. Además, argumentan que el régimen comercial de la $\mathrm{OMC}$ debe prevalecer sobre cualquier otro acuerdo.

A comienzos del 2000, se logró un acuerdo unánime aprobando el Protocolo de Cartagena sobre Bioseguridad.

El Protocolo diferencia dos casos de organismos transgénicos, unos que son los que se introducen al medio para el cultivo, como por ejemplo las semillas y otros, que se incorporan al procesamiento y consumo, humano y animal, como los granos transgénicos (maíz, trigo, soya, etc.)

El protocolo establece que cada país adopte sus regulaciones nacionales respecto de los alimentos transgénicos y acepte que tal reglamento pueda ser más exigente que las normativas del mismo Protocolo, pero exige que se notifique a las demás naciones.

El Acuerdo Informado Previo, se refiere esencialmente al comercio de semillas transgénicas permitiendo imponer restricciones a su comercio pero no a su cultivo

Pero en aquellos organismos transgénicos destinados al procesamiento y consumo no se exige el Acuerdo Fundamentado Previo, se puede aceptar el acceso cono sin condiciones, prohibir su entrada o prorrogar el plazo por un tiempo determinado de la entrada del organismo modificado.

El Protocolo incluye el Principio de Precaución o Precautorio que es la base para proteger el medio ambiente y a los consumidores cuando no se cuenta con evidencia científica suficiente.

El Protocolo regula exclusivamente los movimientos transfronterizos de los alimentos agrícolas transgénicos, para evitar riesgos ambientales y sanitarios. El Protocolo no regula todos los aspectos de la bioseguridad por lo que las leyes nacionales deben cubrir los vacíos. $\mathrm{El}$ Protocolo y la OMC se apoya mutuamente, el primero, con base en el Principio Precautorio y el segundo, en la suficiente evidencia científica. 


\section{Enrique Palacios Lozada}

La diversidad biológica y la seguridad alimentaría no prevalecen sobre las normas de la OMC y viceversa, es decir, ninguno de ellos queda subordinado al otro.

\section{ORGANIZACIÓN MUNDIAL DE COMERCIO}

La (OMC) fue establecida en 1995 entre sus funciones está el resolver las controversias comerciales entre sus miembros, le otorgaron un mandato para desarrollar estándares de seguridad alimentaría, pero solo cuentan con disciplinas para evitar que los miembros utilicen innecesariamente y sin justificación barreras técnicas como barreras al comercio. Estas normativas se enmarcan especialmente en los Acuerdos sobre Medidas Sanitarias y Fitosanitarias, en el de Barreras Técnicas al Comercio, y en el Acuerdo de Propiedad Intelectual relacionados con el comercio (ADPIC).

El país tiene el derecho de establecer sus propias normas ambientales y de seguridad alimenticia en el ámbito nacional, Sin embargo, este derecho debe ser consistente con los principios de la OMC.

En relación con los productos transgénicos, no existe en la OMC un compromiso que regule su comercio. Las reglas del comercio internacional han dirigido su atención al comercio de productos y no a los procesos y métodos de producción, a excepción que el proceso productivo afecte la seguridad del recurso natural y la salud humana y animal colocándola en peligro.

En general, la legislación nacional e internacional al control de los organismos transgénicos es aún escasa.

Existen algunas diferencias entre el (CDB)Convenio de Biodiversidad y el (ADPIC) Acuerdo sobre los derechos de Propiedad Intelectual que generan conflictos. Para el Convenio de Biodiversidad, el derecho sobre el recurso biológico le pertenece al Estado, en cambio por el Acuerdo los recursos genéticos están sujetos a derechos privados. Un segundo 


\section{La producción y el comercio de los productos transgénicos}

problema se genera en torno a los beneficios por el uso de estos recursos por el cual el Convenio debe dar lugar a dividendos equitativos, en tanto el Acuerdo al conceder las patentes a los agentes privados, no considera que los mismos deban ser compartidos.

Por el ADPIC, los países miembros de la OMC, están obligados a otorgar una patente a los descubrimientos relativos a los productos derivados de microorganismos y procesos biológicos que se emplean en todos los campos tecnológicos, y en ella, la biotecnología. Sin embargo, el descubrimiento del material biológico o la información genética no es patentable según el Acuerdo en tanto, que quienes manipulan este material lo consideran una innovación, y por lo tanto, con derecho a una patente.

Los intereses son distintos, entre aquellos que desean conservar estos recursos, y aquellos que desean hacer uso de ellos, la propiedad y control de los recursos genéticos constituye uno de los temas más controvertidos a los que se enfrentan la sociedad. Los países están conscientes que los recursos genéticos son valiosos y que deben cuidarse para futuras generaciones. Los países ricos en biodiversidad suele ser los países en desarrollo, los que reclaman el derecho a que sus recursos sean valorados y se les compense por su disponibilidad. El debate por los derechos de los recursos genéticos continúa.

La biotecnología ha permitido que privados puedan adueñarse de información o tecnologías que tradicionalmente han pertenecido al dominio público. Se han ido cambiando las formas de producción, quedando especialmente afectados los métodos tradicionales basados en conocimientos transmitidos por generaciones. Se protege el derecho de propiedad de los nuevos conocimientos vía patentes, pero no se quiere respetar la propiedad a la biodiversidad y al conocimiento ancestral.

Este tratamiento asimétrico del conocimiento y del derecho a la propiedad exige por parte de los Estados que se sientan afectados aplicar normas nacionales para proteger su biodiversidad y conocimiento ancestral. 


\section{Enrique Palacios Lozada}

\section{APRECIACIONES FINALES}

El tema de los transgénicos es controversial por un lado las grandes ventajas generadas por la aplicación de técnicas biotecnológicas en la creación de nuevas variedades mas productivas y resistentes a pesticidas, herbicidas y a enfermedades y plagas.

Por otro lado la desventajas que ofrece su uso al entrañar posibles riesgos para la salud humana, animal y al medioambiente.

Al margen de esta controversia de aplicación científica, encontramos que las nuevas tecnologías requieren significativas Inversiones en Investigación, las cuales son realizadas por los paises en desarrollo especialmente por las empresas Transnacionales, las cuales ejercen un dominio de producción y comercio de los transgénicos. Donde los países en desarrollo se constituyen en simples receptores.

Lo cierto es que la agrobiotecnologia es solo una continuación de la agricultura de altos insumos donde la aplicación del conocimiento genético a través de la Ingeniería Genética, la técnica del ADN recombinante, pueden ayudar a satisfacer en un futuro cercano las necesidades alimenticias de la población mundial, los posibles efectos negativos pueden ser resueltos con investigaciones futuras.

Sin embargo las investigaciones están orientadas a productos de consumo masivo: soya, maíz, colza, etc. Visto desde un punto de negocio.

Los paises como el nuestro requieren hacer investigaciones biotecnológicas con aplicación en:

- Productos nativos y andino

- Aprovechar nuestra biodiversidad.

Se tiene recursos humanos calificados en el manejo de estas técnicas biotecnológicas, siendo imprescindible la decisión del Estado y el sector privado en realizar las Inversiones que se requieren, dado que la Invención es un Instrumento de Desarrollo. 
La producción y el comercio de los productos transgénicos

\section{BIBLIOGRAFIA}

Ablin, Eduardo y Santiago Paz El Debate Internacional sobre productos transgénicos. Opciones para las exportaciones agrícolas Argentina. Boletín Technit 2001. Argentina.

Andrade, F.H. ¿Es posible satisfacer la creciente demanda de alimentos de la humanidad?. 1998.

Berthelot, James. L`Agricultura Talon d`Achile de la Mondiaisation. 2001- France.

Barcena, Alicia, Jorge Katz y otros. Los transgénicos en América Latina y El Caribe: un debate abierto. CEPAL 2004

Grobman, Alexander. Los transgénicos en América Latina y El Caribe: Un debate abierto. CEPAL-2004

Heineke, Corinna. La vida en Venta: Transgénicos patentes y biodiversidad. Perú 2002. Larach, Maria Angélica. El Comercio de los productos transgénicos: el estado del debate internacional. CEPAL-2001.

Morales, César. Las nuevas fronteras tecnológicas: Promesas, desafíos y amenazas de los transgénicos CEPAL-2001. 